\title{
Rapid Tryptophan Depletion Plus a Serotonin 1A Agonist: Competing Effects on Sleep in Healthy Men
}

Polly Moore, Ph.D., Erich Seifritz, M.D., Arlene Schlosser, Debbie Greenfield, M.A., Steven Stahl, M.D., Mark Rapaport, M.D., John Kelsoe, M.D.

In the present study, we hypothesized that the REMsuppressing effects of $5-\mathrm{HT}_{1 \mathrm{~A}}$ receptor stimulation would counteract the REM-disinhibiting effects of rapid tryptophan depletion (RTD), and vice versa. We administered RTD plus ipsapirone (10 mg, p.o.) or RTD plus placebo to 10 healthy men. In contrast to our previous findings but partially consistent with other studies, RTD in combination with placebo did not produce a significant enhancement of any REM sleep measure. The combination of RTD and ipsapirone produced a significant suppression of REM sleep that was remarkably similar to the effect of ipsapirone alone. These data appear to deepen the mystery of variable and inconsistent $R T D$-induced responses in healthy subjects. In the case of REM sleep measures, this differs markedly from the consistent RTD-induced REMdisinhibiting effect seen in medicated depressed patients. [Neuropsychopharmacology 25:S40-S44, 2001] (C) 2001 American College of Neuropsychopharmacology. Published by Elsevier Science Inc.
KEY WORDS: 5-HT; Serotonin; Tryptophan; Rapid tryptophan depletion; Depressive disorders; 5-HT1A receptor; Ipsapirone; Sleep

The rapid tryptophan depletion (RTD) paradigm (Young et al. 1985; Delgado et al. 1990) allows researchers to study the consequences of 5-HT system deactivation. In humans and animals, RTD has been shown to cause significant (but transient) reductions in the levels of tryptophan (TRP) in the blood, and to reduce the amount of 5-HT in the brain (for review, see Moore et

From the National Multi-Site Training Program in Basic Sleep Research, UCLA Neuroscience Interdepartmental Graduate Program and Brain Research Institute, Los Angeles, CA (PM), Department of Psychiatry, University of California at San Diego, San Diego, CA (UCSD) Mental Health Clinical Research Center (PM, ES, AS, DG, SS, MR, JK), Veterans Affairs San Diego Healthcare System, 3350 La Jolla Village Drive, San Diego, CA 92161 (AS, DG), UCSD Cancer Center (PM), San Diego, CA.

Address correspondence to: Polly Moore, Ph.D., UCSD Cancer Center and Department of Psychiatry, 9500 Gilman Drive (mail code 0804), San Diego, CA 92093-0804, Tel.: (619) 543 3441, Fax: (619) 543 5462, E-mail: pmoore@ucsd.edu al. 2000). RTD typically consists of a day's worth of a low-TRP diet, followed by ingestion of a TRP-free amino acid load, and RTD, but not the control TRP-containing condition, has been associated with myriad clinical and physiological effects. Relapse of depressive mood following RTD in recently remitted depressed patients has been reported (Delgado et al. 1990). In healthy subjects, mood responses as well as other behavioral measures have been somewhat inconsistent (Young et al. 1985; Barr et al. 1997).

The sleep abnormalities often associated with depression are consistent with the notion of a pathophysiologic deficiency in serotonergic function in depression (Maes and Meltzer 1995). There is strong preclinical and clinical evidence that serotonin plays a role in suppressing REM sleep (McGinty and Harper 1976; Honda and Semba 1994; Luebke et al. 1992; Portas et al. 1996).

RTD apparently disinhibits REM sleep measures in serotonin reuptake inhibitor (SRI)-treated patients in full remission (Moore et al. 1998) and in healthy male control subjects (Bhatti et al. 1998), using two different 
strengths of RTD (100\% and 25\%). In SRI-treated patients, both RTD doses also reversed the reduced total sleep time and prolonged sleep latency observed at baseline. In normal males, both RTD doses significantly decreased REM latency compared with baseline, as well as significantly reduced total and free plasma TRP concentrations.

Agonists at the 5- $\mathrm{HT}_{1 \mathrm{~A}}$ receptor, such as ipsapirone, have been shown to inhibit REM sleep both in healthy subjects and in depressed patients (Gillin et al. 1994; Gillin et al. 1996; Seifritz et al. 1998), and this effect presumably reflects predominantly post-synaptic receptor activity. In the present study, we examined the competing effects of 5-HT depletion and 5-HT stimulation on sleep. We predicted REM sleep measures with RTD plus placebo would be significantly enhanced compared with baseline as shown in previous studies with RTD alone, and that the combination of RTD and ipsapirone would produce REM measures with values intermediate between those obtained with either 5-HT manipulation alone.

\section{METHODS}

\section{Subjects}

Ten healthy male subjects between the ages of 20 to 39 years $(28.7 \pm 1.9$, mean $\pm \mathrm{SD})$ were recruited from the general public in the San Diego region through the UCSD Mental Health Clinical Research Center (MHCRC). Eight Caucasian-Americans and two AfricanAmericans completed the study after giving written informed consent (approved by UCSD Human Subjects Committee). Routine MHCRC screening methods, and inclusion and exclusion criteria have been described elsewhere (Bhatti et al. 1998). Patients self-reported no personal or family history of psychiatric disorders.

\section{Procedures}

Nocturnal sleep studies were conducted in the sleep laboratory in the San Diego Veteran's Affairs Medical Center (SDVAMC). Bedtime was set as close as possible to the subject's customary bedtime on all nights; care was taken to ensure night-to-night consistency in this regard. The adaptation night screened for sleep disorders. All pre-bedtime tasks and questionnaires were completed at approximately the same time relative to bedtime each night. Pre-challenge baseline recordings were run the night directly preceding the challenge night. On RTD challenge nights, a TRP-free RTD was ingested at about 5:30 P.M.; then, in double-blind fashion, $10 \mathrm{mg}$ ipsapirone or placebo was administered 20 min prior to bedtime. These schedules were intended to maximize the effects of each of these treatments on sleep, based upon our experience. Ipsapirone has a plasma half-life of $1-2 \mathrm{~h}$ and its sleep effects appear to be greatest when taken at bedtime. The maximal tryptophan-depleting effects of the RTD (as measured by plasma TRP levels, which are roughly coincident with the sleep effects we have seen) occur within 5-10 h after ingestion of the drink. Challenge nights were separated by one week.

Polysomnographic Recordings. Sleep recordings were conducted and scored according to standard technique, and as described and defined previously (Moore et al. 1998). Sleep variables were Total Sleep Time, Sleep Efficiency, Sleep Latency, Wakefulness after sleep onset, REM minutes, REM percent, REM latency, REM latency-corrected, REM density.

Rapid Tryptophan Depletion Paradigm. The RTD protocol was conducted virtually identically to previous studies with one exception, that is, the composition of the RTD was altered slightly, lessened in strength from $100 \%$ (102.5 gm) to $85 \%$ and adjusted to the individual's body weight, in a fixed ratio $(85 \% / 70 \mathrm{~kg})$. Comparing pre-RTD baseline to 5-h post-RTD tryptophan levels, this composition decreased plasma TRP similarly to the $100 \%$ strength RTD. Low-TRP diet, free and total plasma TRP analysis were conducted as in previous studies. Mood scales (Visual Analog Scale, [VAS]; Profile of Mood States [POMS]; a symptom checklist, and perceived sleep quality questionnaires were filled out on multiple occasions.

\section{Data Analysis}

Within-subjects repeated measures analyses of variance (ANOVA) were performed on one or more variables (mood, plasma tryptophan, polysomnographic sleep measures) compared across four conditions (RTD plus ipsapirone, RTD plus placebo, and both pre-challenge baseline nights). All variables were initially examined for normality of distribution using Kolmogorov statistics. Data are expressed as means \pm s.e.m. Level of significance was set at $\alpha<0.05$. For sleep measures and mood data, $\mathrm{n}=10$; for plasma data, $\mathrm{n}=9$.

\section{RESULTS}

\section{Plasma Tryptophan Measures}

The combination of treatments (RTD plus ipsapirone, RTD plus placebo) was well tolerated by all subjects. Total and free plasma TRP concentrations ( $\mu \mathrm{mol} / \mathrm{l})$ were significantly reduced $5 \mathrm{~h}$ post-ingestion after both RTD trials $(p<.001$ repeated measures ANOVA with pairwise pre versus post-RTD comparison). Free plasma TRP decreased by $78 \%$ and $80 \%$, respectively, in the two challenges. Total TRP decreased by $92 \%$ after both challenges. 


\section{Polysomnographic Sleep Measures}

As shown in Table 1, ANOVAs revealed significant differences across the four nights of sleep on measures of REM-latency $\left(\mathrm{F}_{(1,9)}=22.84, p<.001\right)$ and REM-latencycorrected $\left(\mathrm{F}_{(1,9)}=11.03, p<.01\right)$. There were no significant differences seen in REM min, REM\%, nor REM density, or of total sleep time and sleep latency. Post hoc pairwise comparisons showed that the significant differences were due to sleep effects only when the RTD plus ipsapirone condition was compared with its preceding baseline recording night. RTD plus placebo did not differ significantly from baseline on any sleep measure.

\section{Mood Measures}

There were no significant short-term effects on mood of neither RTD nor ipsapirone (data not shown). There were also no significant findings from any item on the subjective sleep questionnaire (data not shown).

\section{DISCUSSION}

Free and total plasma TRP levels were significantly lowered $5 \mathrm{~h}$ post-RTD compared with baseline levels, to an extent comparable to other published studies, including our own. However, the REM sleep findings of our earlier RTD study in healthy subjects were not replicated, and were partially consistent with other reports (Voderholzer et al. 1998). We had predicted that: 1) after RTD plus placebo, REM measures would be disinhibited compared with baseline conditions, and 2) after
RTD plus ipsapirone, REM measures would approximate baseline values. Neither prediction was borne out. RTD plus placebo in this study did not significantly shorten REM latency, and REM min, REM\%, and REM density were not significantly increased. All significant changes from baseline of sleep in this study were essentially restricted to the REM-suppressing effects of $10 \mathrm{mg}$ ipsapirone (prolonged REM-latency and REM-latencycorrected on RTD plus ipsapirone night).

It is unclear why these data are inconsistent with previous reports. Here, after an 85\% RTD, REM latency was $69 \pm 5$ (mean \pm s.e.m.), whereas in the Bhatti et al. (1998) study after the $100 \%$ RTD, mean REM-latencies were $40 \pm 11$, and $48 \pm 12$ after the $25 \%$ RTD. Baseline REM latencies did not differ significantly between the studies, nor did subject age. Examining REM-latency changes from baseline across both studies, in our opinion, each of the 21 subjects can be classified as either a responder or a non-responder to RTD. In the previous RTD-only study, after the $100 \%$ RTD, five of 11 subjects demonstrated a sleep onset REM period (SOREMP, REM latency $<20 \mathrm{~min}$ ). Two of the $11 \mathrm{had}$ a SOREMP after the $25 \%$ RTD. In the RTD plus ipsapirone study reported here, there were no SOREMPs. Participants in both studies had been screened in the same fashion, including for family history of affective illness.

Pronounced individual and gender-related differences in rates of 5-HT synthesis are suggested by PET data (Nishizawa et al. 1997). We wonder if individual regulatory differences in the serotonin system itself (possibly genetic) may determine whether or not a subject "responds" to RTD. If so, such differences in vulnerability to RTD may have implications for the

Table 1. Summary of Sleep Statistics for the Pre-Challenge Baseline and RTD Challenge Nights in the Placebo and Ipsapirone Conditions

\begin{tabular}{|c|c|c|c|c|}
\hline Sleep variable & $\begin{array}{c}\text { Pre-placebo } \\
\text { baseline }\end{array}$ & $\begin{array}{l}\text { RTD + } \\
\text { placebo }\end{array}$ & $\begin{array}{l}\text { Pre-drug } \\
\text { baseline }\end{array}$ & $\begin{array}{c}\text { RTD + } \\
\text { ipsapirone }\end{array}$ \\
\hline Total sleep time (min) & $395 \pm 7$ & $400 \pm 7$ & $389 \pm 6$ & $386 \pm 5$ \\
\hline Sleep latency $(\mathrm{min})$ & $12 \pm 2$ & $10 \pm 2$ & $12 \pm 2$ & $13 \pm 3$ \\
\hline REM latency (min) & $70 \pm 4$ & $69 \pm 5$ & $70 \pm 13$ & $147 \pm 18^{\#, *}$ \\
\hline REM latency-corr. (min) & $67 \pm 4$ & $65 \pm 4$ & $66 \pm 12$ & $98 \pm 12^{\#, *}$ \\
\hline REM density & $1.6 \pm 0.1$ & $1.7 \pm 0.1$ & $1.8 \pm 0.1$ & $1.7 \pm 0.1$ \\
\hline REM duration (min) & $90 \pm 8$ & $93 \pm 6$ & $90 \pm 8$ & $80 \pm 6$ \\
\hline REM\% of total sleep time & $22 \pm 1.1$ & $23 \pm 1.5$ & $23 \pm 1.5$ & $20 \pm 1.5$ \\
\hline Duration of 1st REM (min) & $18 \pm 1.8$ & $17 \pm 1.7$ & $17 \pm 1.6$ & $17 \pm 1.7$ \\
\hline Wake after sleep onset (min) & $22 \pm 5$ & $20 \pm 3$ & $25 \pm 4$ & $27 \pm 5$ \\
\hline \multicolumn{5}{|l|}{ Sleep efficiency \% } \\
\hline (sleep min $\div$ time in bed) & $91 \pm 1.3$ & $91 \pm 0.9$ & $90 \pm 1.2$ & $89 \pm 1.5$ \\
\hline St $1 \%$ of total sleep time & $5 \pm 0.9$ & $6 \pm 0.9$ & $6 \pm 0.9$ & $6 \pm 0.9$ \\
\hline St $2 \%$ of total sleep time & $58 \pm 1.8$ & $58 \pm 2.0$ & $60 \pm 1.7$ & $60 \pm 1.5$ \\
\hline St $3 \%$ of total sleep time & $8 \pm 1.2$ & $7 \pm 1.0$ & $7 \pm 1.1$ & $7 \pm 1.0$ \\
\hline St $4 \%$ of total sleep time & $6 \pm 1.4$ & $6 \pm 1.4$ & $4 \pm 1.4$ & $5 \pm 1.4$ \\
\hline
\end{tabular}

Means \pm s.e.m.

\#Overall ANOVA $(\mathrm{df}=1,9), p<.05$

*Post-hoc pairwise comparisions significant vs preceding baseline night 
plethora of conflicting findings in healthy subjects using a variety of behavioral measures, for example, mood (e.g., Young et al. 1985; Barr et al. 1997), anxiety and panic (Goddard et al. 1995; Klaassen et al. 1998), aggression (Cleare and Bond 1995; Bjork et al. 1999), food choices (Oldman et al. 1994; Young et al. 1988), as well as REM sleep. The variability in the RTD-induced REM responses of healthy subjects contrasts dramatically with the consistent REM-disinhibiting effects of RTD in depressed patients treated with SRIs (Moore et al. 1998) or monoamine oxidase inhibitors (Landolt et al. 2000).

In summary, this study failed to demonstrate that the REM-suppressing effects of ipsapirone, a $5-\mathrm{HT}_{1 \mathrm{~A}}$ agonist, could counteract the REM sleep-disinhibiting effects of tryptophan depletion. However, the study failed to do so because neither the REM sleep findings nor the subjective mood findings of our previous RTD report in healthy men were replicated, despite significant and comparable plasma depleting effects of RTD. We believe there are important individual differences in vulnerability to RTD. The medical or psychiatric factors that may be associated with this vulnerability are unknown.

\section{ACKNOWLEDGMENTS}

Research supported by grants from: the UCSD General Clinical Research Center's Program (Michael Ziegler, MD, Director, MOI RR00827); National Institutes of Health (MH 57134-01, MH 18825 and CA23100); UCSD Mental Health Clinical Research Center (MH 30914) and Department of Veterans Affairs; and the Stanley Foundation. ES is supported by Swiss National Foundation grant \# 63-58040.99.

\section{REFERENCES}

Barr LC, Heninger GR, Goodman W, Charney DS, Price LH (1997): Effects of fluoxetine administration on mood response to tryptophan depletion in healthy subjects. Biol Psychiatry 41:949-954

Bhatti T, Gillin JC, Seifritz E, Moore P, Clark C, Golshan S, Stahl S, Rapaport M, Kelsoe J (1998): Effects of a tryptophan-free amino acid drink challenge on normal human sleep EEG and mood. Biol Psychiatry 43:52-59

Bjork JM, Dougherty DM, Moeller FG, Cherek DR, Swann AC (1999): The effects of tryptophan depletion and loading on laboratory aggression in men: time course and a food-restricted control. Psychopharmacology 142:24-30

Cleare AJ, Bond AJ (1995): The effect of tryptophan depletion and enhancement on subjective and behavioral aggression in normal male subjects. Psychopharmacology 118:72-81

Delgado PL, Charney DS, Price LH, Aghajanian GK, Landis H, Heninger GR (1990): Serotonin function and the mechanism of antidepressant action: reversal of antidepressant-induced remission by rapid depletion of plasma tryptophan. Arch Gen Psychiatry 47:411-418
Gillin JC, Jernajczyk W, Valladares-Neto DC, Golshan S, Lardon M, Stahl S (1994): Inhibition of REM sleep by ipsapirone, a $5 \mathrm{HT} 1_{\mathrm{A}}$ agonist, in normal volunteers. Psychopharmacology 116:433-436

Gillin JC, Buchsbaum MS, Valladares-Neto DC, Hong CCH, Hazlett E, Langer SZ, Wu J (1996): Effects of zolpidem on local cerebral glucose metabolism during nonREM sleep in normal volunteers: A positron emission tomography study. Neuropsychopharmacology 15: 302-313

Goddard AW, Charney DS, Germine M, Woods SW, Heninger GR, Krystal JH, Goodman WK, Price LH (1995): Effects of tryptophan depletion on responses to yohimbine in healthy human subjects. Biol Psychiatry 38:74-85

Honda T, Semba K (1994): Serotonergic synaptic input to cholinergic neurons in the rat mesopontine tegmentum. Brain Res 576:157-161

Klaassen T, Klumperbeek J, Deutz NEP, van Praag HM, Griez E (1998): Effects of tryptophan depletion on anxiety and on panic provoked by carbon dioxide challenge. Psychiatry Res 77:167-174

Landolt HP, Schnierow JB, Kelsoe JR, Rapaport MH, Gillin JC (2000): Phenelzine-induced suppression of REM sleep can be reversed by rapid tryptophan depletion. Sleep 23(Suppl 2):A34

Luebke JI, Greene RW, Semba K, Kamondi A, McCarley RW, Reiner PB (1992): Serotonin hyperpolarizes cholinergic low-threshold burst neurons in the rat laterodorsal tegmental nucleus in vitro. Proc Natl Acad Sci USA 89:743747

Maes M, Meltzer HY (1995): The serotonin hypothesis of major depression. In FE Bloom, DJ Kupfer (eds), Psychopharmacology: The Fourth Generation of Progress. New York, Raven Press, pp 933-944

McGinty DJ, Harper RM (1976): Dorsal raphe neurons: depression of firing during sleep in cats. Brain Res 101:569-575

Moore P, Gillin JC, Bhatti T, DeModena A, Seifritz E, Clark C, Stahl S, Rapaport M, Kelsoe J (1998): Rapid tryptophan depletion, sleep electroencephalogram, and mood in men with remitted depression on serotonin reuptake inhibitors. Arch Gen Psychiatry 55:534-539

Moore P, Landolt H, Seifritz E, Clark C, Kelsoe J, Rapaport M, Bhatti T, Gillin JC (2000): Clinical and physiological consequences of rapid tryptophan depletion. Neuropsychopharmacology 23:601-622

Nishizawa S, Benkelfat C, Young SN, Leyton M, Mzengeza S, de Montigny C, Blier P, Diksic M (1997): Differences between males and females in rates of serotonin synthesis in human brain. Proc Natl Acad Sci USA 94:5308-5313

Oldman AD, Walsh AES, Salkovskis P, Laver DA, Cowen PJ (1994): Effect of acute tryptophan depletion on mood and appetite in healthy female volunteers. J Psychopharmacol 8:8-13

Portas CM, Thakkar M, Rainnie D, McCarley RW (1996): Microdialysis perfusion of 8-hydroxy-2-(Di-n-propylamino)tetralin (8-OH-DPAT) in the dorsal raphe nucleus decreases serotonin release and increases rapid eye movement sleep in the freely moving cat. J Neurosci $16: 2820-2828$

Seifritz E, Gillin JC, Rapaport MH, Kelsoe JR, Bhatti T, Stahl 
SM (1998): Sleep EEG response to muscarinic and serotonin $_{1 \mathrm{~A}}$ receptor probe in patients with major depression and normal controls. Biol Psychiatry 44:21-33

Voderholzer U, Hornyak M, Thiel B, Huwig-Poppe C, Kiemen A, Konig A, Backhaus J, Riemann D, Berger M, Hohagen F (1998): Impact of experimentally induced serotonin deficiency by tryptophan depletion on sleep EEG in healthy subjects. Neuropsychopharmacology 18:112-124
Young SN, Smith SE, Pihl RO, Ervin FR (1985): Tryptophan depletion causes a rapid lowering of mood in normal males. Psychopharmacology 87:173-177

Young SN, Tourjman SV, Teff KL, Pihl RO, Anderson GH (1988): The effect of lowering plasma tryptophan on food selection in normal males. Pharm Biochem Behav 31:149152 